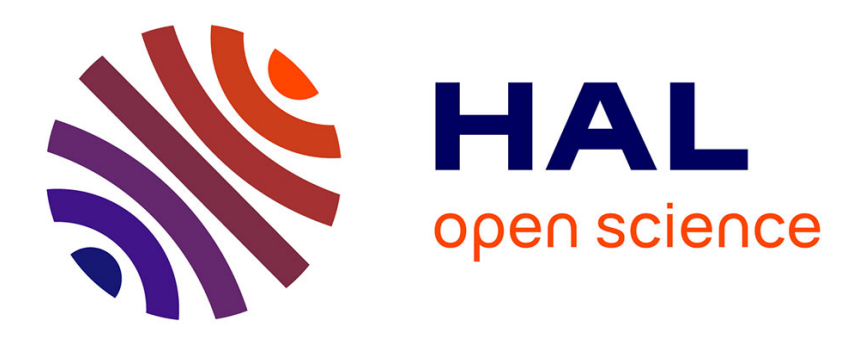

\title{
Kinetics of the electrochemically-assisted deposition of sol-gel films
}

\author{
Liang Liu, Alain Walcarius
}

\section{To cite this version:}

Liang Liu, Alain Walcarius. Kinetics of the electrochemically-assisted deposition of sol-gel films. Physical Chemistry Chemical Physics, 2017, 19 (23), pp.14972 - 14983. 10.1039/c7cp01775h . hal01804035

\section{HAL Id: hal-01804035 \\ https://hal.science/hal-01804035}

Submitted on 16 Feb 2022

HAL is a multi-disciplinary open access archive for the deposit and dissemination of scientific research documents, whether they are published or not. The documents may come from teaching and research institutions in France or abroad, or from public or private research centers.
L'archive ouverte pluridisciplinaire HAL, est destinée au dépôt et à la diffusion de documents scientifiques de niveau recherche, publiés ou non, émanant des établissements d'enseignement et de recherche français ou étrangers, des laboratoires publics ou privés. 


\title{
Kinetics of the electrochemically-assisted deposition of sol-gel films
}

\author{
Liang Liu*, Alain Walcarius \\ Laboratoire de Chimie Physique et Microbiologie pour l'Environnement, UMR 7564, CNRS-Université \\ de Lorraine, 405 rue de Vandoeuvre, 54600 Villers-lès-Nancy, France \\ *Email: liang.liu@univ-lorraine.fr
}

\begin{abstract}
Electrochemically-assisted deposition is now becoming a widespread method for preparing sol-gel films. It is based on the electrochemical generation of $\mathrm{OH}^{-}$ions which catalyze the sol-gel condensation reactions. It has a key advantage of selectively facilitating the film deposition on electrochemically active surfaces while not affecting the stability of the bulk precursor solution. Experimental works have clearly shown that the thickness of electrochemically-assisted deposited films is influenced by deposition parameters such as potential and time. However, there is still lack of quantitative description for the kinetics of film growth due to the complexity of the process. In this preliminary work, we have derived quantitative analytical expressions for describing the kinetics associated to the growth of sol-gel films generated by electrochemically-assisted deposition. Both the heterogeneous and homogeneous condensation reactions are considered. The key strategy is to simplify the process by separating the electrochemical step of generating $\mathrm{OH}^{-}$ions with the condensation steps of film formation under approximations. Furthermore, numerical simulation is carried out to examine the validity and error of the analytical expressions in the cases when the required approximations are not fulfilled. The analytical expressions can well explain the trends observed in experimental works, and can be used for fitting the experimental results from literature. This work provides a deeper understanding of the mechanism and a quantitative guidance for manipulating the electrochemically-assisted deposition processes at large scale in industry. It may also be referred by other indirect electrodeposition systems in which the deposition is not an electrochemical step but is driven by electrochemically generated catalysts. Keywords: electrochemically-assisted deposition, sol-gel, thin films, kinetics, simulation
\end{abstract}




\section{Introduction}

Sol-gel is an ancient process dating back to mid- $19^{\text {th }}$ century, when Ebelmen and Graham ${ }^{1-3}$ found that tetraethoxysilane (TEOS) can hydrolyze in acidic media forming glass-like transparent $\mathrm{SiO}_{2}$. Later the technique became an important method for preparing materials and thin films of various oxides ${ }^{4}$. Sol-gel reactions are usually operated under mild conditions, so it may serve as a media for embedding functional species such as nanoparticles ${ }^{5,6}$, catalysts ${ }^{7}$, enzymes $^{8}$ and bacteria 9.

Usually, sol-gel films are prepared by dip-coating, spin-coating and spraying ${ }^{10-12}$. These methods involve a sol solution containing a suitable precursor (typically a tetraalkoxysilane or sodium silicate in hydroalcoholic medium), and the film deposition is induced by the evaporation of solvent or the addition of catalysts (e.g. $\mathrm{HCl}$ or $\left.\mathrm{NH}_{3} \cdot \mathrm{H}_{2} \mathrm{O}\right)$. On one hand, the sol precursor must be stable enough for the operation, but on the other hand the gelation should be facilitated for film deposition. Delicate optimization is required to achieve their balance, and it also depends on environmental parameters such as humidity ${ }^{12}$.

Electrochemically-assisted deposition, which was first clearly proposed in $1999^{13}$, provided an elegant strategy to solve the problem above. Different from conventional electrodeposition (i.e. reduction of metal ions) or electrophoretic deposition, the approach is based on electrochemically generating $\mathrm{OH}^{-}$ions (by reducing $\mathrm{O}_{2}$ or $\mathrm{H}_{2} \mathrm{O}$ in the sol solution) that catalyzes the gelation of precursors on the electrode surface. It is an indirect electrodeposition process, in which the deposition is not an electrochemical step but is driven by electrochemically generated catalysts. Considering the electrolysis of water as the source for $\mathrm{OH}^{-}$generation and alkoxysilane as sol precursor, the process is depicted in the form of three basic reactions (R1-R3) as follows ${ }^{14}$ :

$$
\begin{aligned}
& \mathrm{H}_{2} \mathrm{O}+\mathrm{e} \rightarrow \mathrm{OH}^{-}+\frac{1}{2} \mathrm{H}_{2} \\
& -\mathrm{SiOH}+\text { Surf-OH } \stackrel{\mathrm{OH}^{-}}{\longrightarrow} \text { Surf-O-Si- }+\mathrm{H}_{2} \mathrm{O} \\
& -\mathrm{SiOH}+-\mathrm{SiOH} \stackrel{\mathrm{OH}^{-}}{\rightarrow}-\mathrm{Si}-\mathrm{O}-\mathrm{Si}-+\mathrm{H}_{2} \mathrm{O}
\end{aligned}
$$

where $-\mathrm{SiOH}$ refers to the silanol groups in prehydrolyzed silane molecules and Surf-OH refers to the hydroxyl groups on the electrode surface. Electrochemically-assisted deposition has a key advantage of 
catalyzing and controlling the deposition process locally on the conductive surface where electrochemical reductions occur. As a result, it can provide the driving force for film deposition while not affecting the stability of the bulk precursor solution, and it can selectively deposit sol-gel films on conductive or highly active parts of substrates. In the past decade, electrodeposition of sol-gel films has been developed for preparing mesoporous silica films ${ }^{15}$, including in their functionalized forms ${ }^{16-19}$, fabricating biosensors ${ }^{20}$, preventing metals from corrosion ${ }^{21}$, etc. This was reviewed in detail in the book chapters by Liu and Mandler ${ }^{14,22}$.

Another advantage of electrochemically-assisted deposition is that the process could be well controlled by tuning deposition parameters such as deposition potential and time, together with the sol composition (precursor concentration, presence of additives). From experimental results, it has been clearly shown that the thickness of the electro-assisted deposited sol-gel films depends on the deposition potential, time and the precursor concentration ${ }^{13,23-25}$. Nevertheless, there is still lack of quantitative description for the kinetics associated to the growth of sol-gel films by electrochemically-assisted deposition. This is mainly due to the complexity of the deposition process. The deposition is governed by the kinetics of R1, and the catalytic behavior of $\mathrm{OH}^{-}$in $\mathrm{R} 2$ and $\mathrm{R} 3$. Moreover, the deposited gel film could reduce the active electrode area and hinder the mass transport of $\mathrm{OH}^{-}$and $-\mathrm{SiOH}$ precursor, affecting the kinetics during the deposition process. All these considerations should be taken into account for establishing the quantitative kinetic model. Quantitatively characterizing the kinetics of film formation would provide deeper understanding of the mechanism of the electrochemically-assisted deposition process. More importantly, it is essential for the electrochemically-assisted deposition to be developed as a matured versatile methodology which will be applicable for large scale film preparation, at the industrial scale for instance.

In this work, quantitative analytical expressions were derived for describing the kinetics of film growth in electrochemically-assisted deposition of sol-gel films under approximated conditions. The alkoxysilane was selected as model system due to the relatively rich experimental data available in the literature for validating the results. Both the heterogeneous and homogeneous condensation reactions were considered. 
The validity of the equations required an approximation that the film formation did not affect the diffusion of $\mathrm{OH}^{-}$ions and the sol monomer, but even when the approximation was not fulfilled the equations could still be applied with acceptable error. This was examined by numerical simulation which purposely introduced different diffusion coefficients for the species in the film and in the solution, as well as the experimental results in literature. Up to our knowledge, this is the first theoretical attempt to explore the quantitative kinetics of the widely applied electrochemically-assisted deposition of sol-gel films. The theory developed may also be generalized for other indirect electrodeposition systems with electrochemically generated catalysts in future.

\section{Theory}

The driving force for the electrochemically-assisted deposition is the electrochemical generation of $\mathrm{OH}^{-}$ ions, which can be achieved by electrolysis of water (R1) or other reactions such as oxygen or nitrate reduction ${ }^{26,27}$. The $\mathrm{OH}^{-}$ions accumulate near the cathode, catalyzing the film formation which involves the heterogeneous chemical adsorption of silanol on the electrode surface (R2) and the homogeneous condensation between silanols (R3). These processes are convoluted. The product of $\mathrm{R} 1$, i.e. $\mathrm{OH}^{-}$, catalyzes the film formation processes $\mathrm{R} 2$ and $\mathrm{R} 3$. At the same time, the deposited film may also reduce the active surface area of the electrode and hinder the mass transport of $\mathrm{OH}^{-}$ions and silanol molecules. The relationship between the electrochemical and chemical processes is neither serial nor parallel, thus the kinetics could not be described by conventional EC or (EC) models. In order to simplify the theoretical treatment, we only considered semi-infinite diffusion of species and neglected the effect of migration and convection. The electrochemical step of generating $\mathrm{OH}^{-}$ions was separated from the condensation steps of film formation. This required an approximation that the deposited film does not significantly affect the kinetics of the electrochemical step (R1) and the mass transport of $\mathrm{OH}^{-}$and silanol (a realistic hypothesis when considering that current transients recorded during potentiostatic sol-gel electrogeneration are almost constant over prolonged deposition times ${ }^{15}$, 24 . Analytical equations were derived under this approximation. Then, we applied finite element method to numerically simulate the 
cases when the approximation was not fulfilled. The simulation results were used to examine the validity and error of the analytical equations. Moreover, the equations were also validated by experimental results from literature.

\subsection{Electrochemical generation of $\mathrm{OH}^{-}$}

The generation of $\mathrm{OH}^{-}$on the cathode is an electrochemical step which constitutes the basis of the electrochemically-assisted deposition process. As already mentioned above, it can be achieved by electrolysis of water, as illustrated in $\mathrm{R} 1$, or other reactions such as oxygen or nitrate reduction ${ }^{26-28}$. In this work, we will not go into the details of the charge transfer kinetics of each possible reaction. Instead, we assume a constant Faraday current $I_{F}$ throughout the deposition process. In this case, the change in the active surface area and the mass transport of the reactant oxygen or nitrate by the deposited film may influence the potential of the electrode, but would not affect the flux of $\mathrm{OH}^{-}$generation on the electrode. It simplifies the mathematics, which is a common treatment in electrodeposition, e.g. Faraday's Law.

Considering the deposition on a planar electrode, the diffusion of the electrochemically generated $\mathrm{OH}^{-}$ ions follows Fick's second Law in a static solution, which can be expressed as follows:

$\frac{\partial C_{O H^{-}}}{\partial t}=D_{O H^{-}} \frac{\partial^{2} C_{O H^{-}}}{\partial x^{2}}$

where $D_{\mathrm{OH}^{-}}$is the diffusion coefficient of $\mathrm{OH}^{-}$in the solution. When the electrode is far away from the counter electrode, the following semi-infinite boundary conditions can be applied:

$C_{O H^{-}}(x, 0)=C_{O H^{-}}^{*}$

$C_{O H^{-}}(\infty, t)=C_{O H^{-}}^{*}$

where $C_{O H^{-}}^{*}$ represents the bulk concentration of $\mathrm{OH}^{-}$ions in the solution. When a constant Faraday current $I_{F}$ is applied, the third boundary condition can be written:

$D_{O H^{-}} \frac{\partial C_{O H^{-}}}{\partial x}=-\frac{I_{F}}{n F A}$ 
where $n$ is the number of electrons for forming one $\mathrm{OH}^{-}$(in most cases $n=1$ ), $F$ is Faraday constant and $A$ is the geometric area of the electrode. With Eq. 1 and boundary conditions Eqs. 2-4, the concentration profile of $\mathrm{OH}^{-}$can be solved:

$C_{O^{-}}(x, t)=C_{O H^{-}}^{*}+\frac{I_{F}}{n F A D_{O H^{-}}}\left[2 \sqrt{\frac{D_{O H^{-}}}{\pi}} e^{-\frac{x^{2}}{4 D_{O H^{-t}}}}-x \operatorname{erfc}\left(\frac{x}{2 \sqrt{D_{O H^{-}}}}\right)\right]$

In practice, the bulk sol solution usually has $\mathrm{pH} 3 \sim 4$ in order to be stable for alkoxysilane hydrolysis and prevent precipitation (forming silica). After applying cathodic potential the $\mathrm{pH}$ near the cathode increases above 8 initiating the deposition, as observed qualitatively by phenolphthalein ${ }^{13}$. The concentration of $\mathrm{OH}^{-}$typically increases by $c a$. $10^{5}$ times at the cathode/solution interface during the electrochemicallyassisted deposition. Even though the $\mathrm{pH}$ of the bulk sol solution may also slightly change due to the insufficient compensation of $\mathrm{H}^{+}$on the anode, the $\mathrm{OH}^{-}$concentration in the bulk solution is still approximately negligible $\left(C_{O H^{-}}^{*} \approx 0\right)$ and $E q .5$ can be simplified:

$C_{O H^{-}}(x, t)=\frac{I_{F}}{n F A D_{O H^{-}}}\left[2 \sqrt{\frac{D_{O H^{-}}}{\pi}} e^{-\frac{x^{2}}{4 D_{O H^{-t}}}}-\operatorname{xerfc}\left(\frac{x}{2 \sqrt{D_{O H^{-}}}}\right)\right]$

Eqs. 5 and 6 are valid for all electrochemical reactions that yield $\mathrm{OH}^{-}$as long as they have the same $n$ value. This avoids dealing with the kinetics of all possible reactions which might affect the film deposition. However, the validation of Eqs. 5 and 6 during the whole deposition period requires a special approximation, that is, the value of $D_{\mathrm{OH}^{-}}$is the same in the deposited film (gel phase) and in the sol solution. Thus it is only applicable when the deposited film is highly permeable to $\mathrm{OH}^{-}$ions, otherwise the presence of the film might affect the diffusion of $\mathrm{OH}^{-}$and thereby change the value of $D_{\mathrm{OH}^{-}}$. When Eqs. 5 and 6 are valid, they can be used in further deriving the kinetics of the adsorption and condensation of silanols (reactions R2 and R3). When the approximation is not fulfilled, the kinetics will be treated by numerical simulation.

\subsection{Film deposition}


It is generally accepted that the sol-gel film formation involves the adsorption of sol components on the surface and the condensation of the sol precursors. The former is a heterogeneous step, while the latter is homogeneous reaction. In terms of alkoxysilane, the processes are expressed as reactions R2 and R3. Note that a fully hydrolyzed alkoxysilane molecule can have multiple silanol groups, and we approximately consider them to be equally reactive. This is a common practice for handling the kinetics of polymerization reactions. Scheme 1 qualitatively describes the sol-gel film formation under electrochemically-assisted deposition. In the heterogeneous route, the silanol groups in hydrolyzed silane molecules react with the hydroxyl groups on the substrate surface via covalent bonding and the adsorbed silane molecules constitute the film. In the homogeneous route, the silanol groups undergo condensation among themselves in the solution. Initially this yields oligomers which are still dissolved in the $\operatorname{sol}^{29}$. Once the oligomers reach a certain degree of polymerization, gel aggregations are formed. Both routes ( $\mathrm{R} 2$ and $\mathrm{R} 3$ ) occur in parallel, and are catalyzed by electrochemically generated $\mathrm{OH}^{-}$ions. They will be discussed separately in the following derivations.

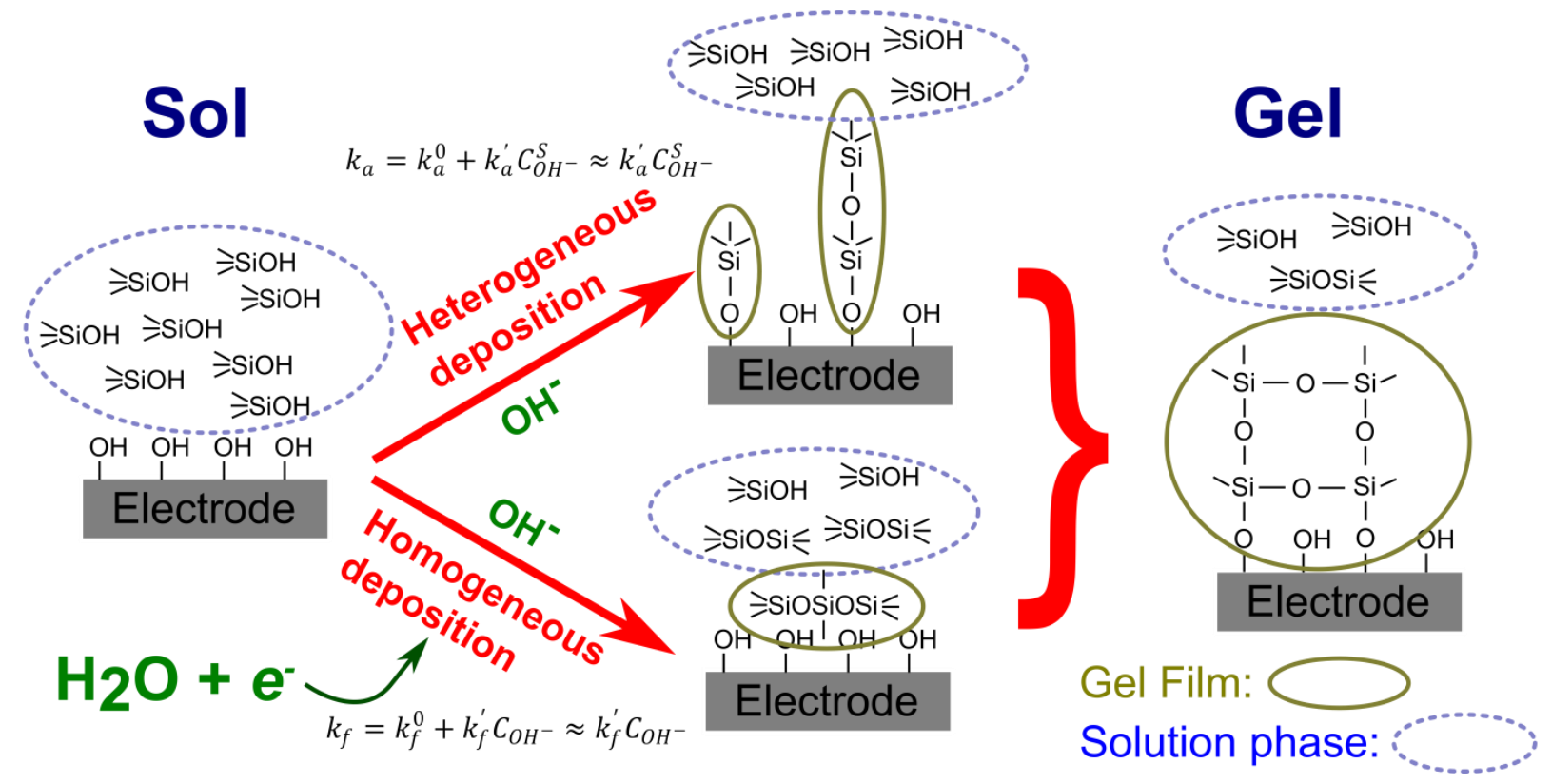

Scheme 1 Electrochemically-assisted deposition of silane sol-gel films based on the heterogeneous and homogeneous condensation of silanol groups. 


\subsubsection{Homogeneous film deposition}

From SEM images in experimental reports ${ }^{15,23,24,30}$, it is seen that most of the thick electrochemicallyassisted deposited silane films consist of silica aggregates (Dry film thickness $>100 \mathrm{~nm}$ ). This suggests that the homogeneous condensation of silanols is dominant in the deposition process, especially for preparing thick films (i.e. typically obtained at long deposition times, highly cathodic polarization, or concentrated precursor solutions). Therefore, we will focus on the homogeneous film deposition in the theory.

From literature ${ }^{31}$, we know that the condensation of silanol is a $S_{N} 2$ reaction and it is irreversible, so the reaction rate of the homogeneous condensation reaction $\mathrm{R} 3$ can be expressed as:

$\frac{d C_{-S i O-}}{d t}=-\frac{d C_{-S i O H}}{d t}=k_{f} C_{-S i O H}^{2}$

where $C_{-\mathrm{SiOH}}$ is the concentration of silanol in terms of $-\mathrm{SiOH}$ groups, and $k_{f}$ is the homogeneous reaction rate constant $\left(\mathrm{m}^{3} \cdot \mathrm{mol}^{-1} \cdot \mathrm{s}^{-1}\right)$. Here, we denote $C_{-S i O-}$ as the concentration of condensed silanol groups instead of the concentration of $-\mathrm{Si}-\mathrm{O}-\mathrm{Si}-$ groups to make clearer the stoichiometry.

Eq. 7 is a pure kinetic expression which does not take into account the mass transport of the reactant. By considering one-dimensional diffusion of silanol moieties, one may have the following equation:

$\frac{\partial C_{-S i O H}}{\partial t}=D_{-S i O H} \frac{\partial^{2} C_{-S i O H}}{\partial x^{2}}-k_{f} C_{-S i O H}^{2}$

in which $D_{-S i O H}$ is the diffusion coefficient of silanol. With the same approximation as for Eqs. 5 and 6, that is, the film deposition does not affect the diffusion of species, $D_{-S i O H}$ can be considered as a constant. The value of $k_{f}$ depends on the solution $\mathrm{pH}$. Considering the base catalysis of silane condensation, the catalytic effect follows general acid-base catalysis, thus $k_{f}$ is proportional to $C_{\mathrm{OH}^{-}}:{ }^{31}$

$k_{f}=k_{f}^{0}+k_{f}^{\prime} C_{O H^{-}}$

where $k_{f}^{0}$ corresponds to the rate constant when there is no catalytic effect, and $k_{f}^{\prime}$ is a kinetic parameter reflecting the catalytic activity of $\mathrm{OH}^{-}\left(\mathrm{m}^{6} \cdot \mathrm{mol}^{-2} \cdot \mathrm{s}^{-1}\right)$. It should be stressed that $E q .9$ is only valid for $\mathrm{C}_{\mathrm{OH}^{-}}>\mathrm{C}_{\mathrm{OH}^{-}}^{*}$, which is obvious in conditions of cathodic electrodeposition, and the acidic catalysis of 
silane condensation is not considered (The condensation rate of most of the alkoxysilanes is the lowest at pH 3-4 ${ }^{31,32}$. In cathodic electrochemically-assisted deposition, the $\mathrm{pH}$ near the cathode will only increase thus the effect of $\mathrm{H}^{+}$is negligible.). In electrochemically-assisted deposition, the solution precursor is usually adjusted to such a favorable $\mathrm{pH}$ for promoting the hydrolysis and minimizing the condensation. From the experimental concern, the starting sol should be presumably stable without applying potential on the electrodes at least for the deposition period. This means the solution does not undergo significant condensation without catalytic effect of $\mathrm{OH}^{-}$so we may consider $k_{f}^{0} \approx 0$. Thus:

$k_{f} \approx k_{f}^{\prime} C_{O H^{-}}$

Unfortunately, it is still impossible to obtain an analytical solution for $E q .8$ due to its non-linearity. Nevertheless, we may consider two extreme cases in which the diffusion of silanol is either very fast or very slow.

Case 1: Fast diffusion of silanol

When the diffusion of silanol is very fast, approximately the concentration of silanol at any position equals to the bulk concentration of silanol (denoted as $\left.C_{-S i O H}^{*}\right)$ :

$C_{-S i O H}=C_{-S i O H}^{*}$

As a result, Eq. 7 becomes:

$\frac{d C_{-S i O-}}{d t}=k_{f} C_{-S i O H}^{* 2}$

Substitute $k_{f}$ with Eq. 10 and $C_{O H^{-}}$with Eq. 6:

$\frac{d C_{-S i O-}}{d t}=k_{f}^{\prime} C_{O H^{-}} C_{-S i O H}^{* 2}=\frac{k_{f}^{\prime} I_{F} C_{-S i O H}^{* 2}}{n F A D_{O H^{-}}}\left[2 \sqrt{\frac{D_{O H^{-}}}{\pi}} e^{-\frac{x^{2}}{4 D_{O H^{-t}}}}-\operatorname{xerfc}\left(\frac{x}{2 \sqrt{D_{O H^{-}}}}\right)\right]$

With initial condition $C_{-S i O}(x, 0)=0$, the concentration profile of condensed silanol groups $C_{-S i O-}$ can be solved:

$C_{-S i O-}=\frac{k_{f}^{\prime} I_{F} C_{-S i O H}^{* 2}}{n F A \sqrt{D_{O H^{-}}}}\left[\frac{4}{3 \sqrt{\pi}}\left(1+X^{2}\right) e^{-X^{2}}-\left(2 X+\frac{4}{3} X^{3}\right) \operatorname{erfc}(X)\right] t^{\frac{3}{2}}$

where $X=\frac{x}{2 \sqrt{D_{O H^{-t}}}}$ 
To get the film thickness as a function of time, one must define the criteria for film formation. The formation of gel film requires a certain degree of silanol polymerization which is known as the gelation point $^{33}$. This can be expressed by a critical concentration of condensed silanol groups denoted as $C_{- \text {SiO- }}^{F}$. When $C_{-S i O-}<C_{-S i O-}^{F}$, the condensation products are oligomers in sol form. They can be washed away when taking the film out from the solution. When $C_{-S i O-}>C_{-S i O-}^{F}$, the condensation products stay as gel film, which can be harvested after deposition and contribute to the film thickness.

From $E q .14$, it is seen that at any time $C_{- \text {SiO- }}$ decreases as $x$ increases. Therefore the film thickness $l$ corresponds to the value of $x$ when $C_{-S i O-}=C_{-S i O-}^{F}$ :

$C_{-S i O-}^{F}=\frac{k_{f}^{\prime} I_{F} C_{-S i O H}^{* 2}}{n F A \sqrt{D_{O H^{-}}}}\left[\frac{4}{3 \sqrt{\pi}}\left(1+L^{2}\right) e^{-L^{2}}-\left(2 L+\frac{4}{3} L^{3}\right) \operatorname{erfc}(L)\right] t^{\frac{3}{2}}$

where $L=\frac{l}{2 \sqrt{D_{\mathrm{OH}^{-}}}}$. By solving $E q .15$, one can obtain $L$ as a function of $t$ and further get $l$ as a function of $t$, which is the variation of film thickness with time. The solution is not explicit but can be solved numerically. Here, a special case in which $l=0$ is concerned. In this case, the $t$ solved corresponds to the onset time of homogeneous film formation. This time is denoted as $t^{F}$ and can be easily calculated from Eq. 15 at $L=0$ :

$t^{F}=\left(\frac{3 n F A C_{-S i O-}^{F} \sqrt{\pi D_{O H^{-}}}}{4 k_{f}^{\prime} I_{F} C_{-S i O H}^{* 2}}\right)^{\frac{2}{3}}$

Eq. 16 suggests that it takes time $t^{F}$ to initiate the homogeneous gelation of silanol in the electrochemically-assisted deposition. Its physical meaning will be discussed later.

\section{Case 2: No diffusion of silanol}

In the previous case just discussed above, we assumed that the diffusion of silanol is very fast so that $E q$. 11 was valid. This could be applicable for the systems with high concentration of silane precursors. When this assumption is not fulfilled, one must consider the diffusion of silanol which consists of two parts. On one hand, the hydrolyzed silanol monomers would diffuse towards the electrode due to the polymerization near the electrode. On the other hand, the polymerized oligomers which usually still consist of high content of silanol groups, would diffuse away in opposite direction to the bulk solution. 
The diffusion in both directions co-exists in the solution where the gel film is not formed (i.e. in a region corresponding to the diffusion layer). As a result, the apparent diffusion coefficient of silanol $D_{O H^{-}}$ should be much lower than common ions $\left(\right.$ e.g. $\left.\mathrm{Na}^{+}, \mathrm{Cl}^{-}\right)$in aqueous solutions. Moreover, in the gel film the silanol groups could be considered as "static". They may still undergo further cross-linking via R3 but are unlikely to diffuse. Therefore, we may consider another extreme case, in which the diffusion of silanol is very slow and $D_{-S i O H} \approx 0$. This means the total concentration of condensed and uncondensed silanol groups, $C_{-S i O H}+C_{-S i O-}$, remains constant all across the solution. Similar treatment has been applied in dealing with the diffusion of reactants and products in electrochemistry, such as for deriving Sand Equation $^{34}$.

With the approximation $D_{-S i O H} \approx 0, E q .7$ becomes:

$\frac{d C_{-S i O H}}{d t}=-k_{f} C_{-S i O H}^{2}$

Similar as in Case 1, the $k_{f}$ can be substituted by Eq. 10 and then $C_{O H^{-}}$can be substituted by Eq. 6 . The initial condition is $C_{-S i O H}(x, 0)=C_{-S i O H}^{*}$. Thus $C_{-S i O H}$ can be solved:

$\frac{1}{C_{-S i O H}}=\frac{1}{C_{-S i O H}^{*}}+\frac{k_{f}^{\prime} I_{F}}{n F A \sqrt{D_{O H^{-}}}}\left[\frac{4}{3 \sqrt{\pi}}\left(1+X^{2}\right) e^{-X^{2}}-\left(2 X+\frac{4}{3} X^{3}\right) \operatorname{erfc}(X)\right] t^{\frac{3}{2}}$

where $X=\frac{x}{2 \sqrt{D_{O H^{-t}}}}$

According to stoichiometry, the critical concentration of uncondensed silanol for film formation has the following relationship:

$C_{-S i O H}^{F}=C_{-S i O H}^{*}-C_{-S i O-}^{F}$

Similar as in $E q .15$, we may substitute $C_{-S i O H}$ with $C_{-S i O H}^{F}$, and further by $E q .19$ to get the film thickness:

$\frac{1}{C_{-S i O H}^{*} C_{-S i O-}^{F}}-\frac{1}{C_{-S i O H}^{*}}=\frac{k_{f}^{\prime} I_{F}}{n F A \sqrt{D_{O H^{-}}}}\left[\frac{4}{3 \sqrt{\pi}}\left(1+L^{2}\right) e^{-L^{2}}-\left(2 L+\frac{4}{3} L^{3}\right) \operatorname{erfc}(L)\right] t^{\frac{3}{2}}$

where $L=\frac{l}{2 \sqrt{D_{O H^{-t}}}}$

Like in Eq. 16, when $x=0, t=t^{F}$, thus:

$t^{F}=\left[\frac{3 n F A \sqrt{\pi D_{O H^{-}}}}{4 k_{f}^{\prime} I_{F}}\left(\frac{1}{C_{-S i O H}^{*}-C_{-S i O-}^{F}}-\frac{1}{C_{-S i O H}^{*}}\right)\right]^{\frac{2}{3}}$ 
Eqs.16 and 21 are two extreme cases, in which the diffusion of - $\mathrm{SiOH}$ is either very fast or very slow. In practice, knowing the parameters $D_{\mathrm{OH}^{-}}, C_{-S i O-}^{F}, C_{-S i O H}^{*}, k_{f}^{\prime}$ and $I_{F}, t^{F}$ should fall between the values as calculated from Eqs. 16 and 21:

$\left(\frac{3 n F A C_{-S i O-\sqrt{\pi D_{O H}}}^{F}}{4 k_{f}^{\prime} I_{F} C_{-S i O H}^{* 2}}\right)^{\frac{2}{3}}<t^{F}<\left[\frac{3 n F A \sqrt{\pi D_{O H}}}{4 k_{f}^{\prime} I_{F}}\left(\frac{1}{C_{-S i O H}^{*}-C_{-S i O-}^{F}}-\frac{1}{C_{-S i O H}^{*}}\right)\right]^{\frac{2}{3}}$

Eq. 22 provides a method of estimating the $t^{F}$ value from the kinetic and experimental parameters. $t^{F}$ is an important parameter in the electrochemically-assisted deposition. When $t<t^{F}$, the degree of polymerization at the electrode surface is not sufficient for inducing homogeneous gelation of silanol. The deposition may only occur via heterogeneous reactions with the electrode surface which will be discussed in the following section 2.2.2. When $t>t^{F}$, homogeneous gelation of silanol occurs in the vicinity of the electrode forming the gel film. The film grows as the deposition time increases, which is due to the expansion of the gelation layer. The value of $t^{F}$, as seen from Eqs. 16 and 21, depends on the critical concentration of condensed silanol $C_{-S i O-}^{F}$, diffusion coefficient of $\mathrm{OH}-$ ions $D_{\mathrm{OH}^{-}}$, kinetic parameter $k_{f}^{\prime}$, applied Faraday current $I_{F}$ and the bulk silanol concentration $C_{-S i O H}^{*}$. Among these parameters, $C_{-S i O-}^{F}$ and $k_{f}^{\prime}$ are related to the gelation which can be analyzed from condensation kinetics in bulk solution, $D_{O H^{-}}$is a constant, and $I_{F}$ and $C_{-S i O H}^{*}$ are controllable experimental parameters.

The physical meaning of $t^{F}$ suggests that it takes time to initiate the homogeneous gelation of silanol in the electrochemically-assisted deposition. The value of $t^{F}$ decreases as $I_{F}$ or $C_{-S i O H}^{*}$ increases, indicating that the homogeneous gelation yielding thick films with aggregates is more favored with high concentration of silane precursor at high deposition current. This is supported by a comprehensive experimental work which reported that the electrochemically-assisted deposition of silane films underwent a "thin to thick" transformation ${ }^{24,25}$. In the beginning of deposition, the films were thin (and well organized in the presence of surfactant), while after a certain time the film thickness dramatically increased and aggregation was formed as seen from ex-situ profilometry and SEM, TEM images. The "thin to thick" transformation time depended on the applied potential, which was monitored by in-situ 
$\mathrm{EQCM}^{24}$. It was also seen that the time for the transformation decreased as the deposition potential was made more negative or the bulk concentration of silane increased. The expressions of $t^{F}$ (Eqs. 16, 21 and 22) clearly confirm the experimental trend. They also offer a quantitative method for analyzing experimental data, which will be discussed later.

\subsubsection{Heterogeneous film deposition}

In Section 2.2.1 it was revealed that $t^{F}$ was required to initiate the homogeneous gelation of the sol-gel solution in the vicinity of the electrode. However, in experimental work it was found that the silane solgel film could also be electrochemically-assisted deposited before $t^{F}$. The deposited films were very thin (tens of nanometers) and may have oriented pores in the presence of surfactant ${ }^{15}$. This could be attributed to the heterogeneous condensation of silanol with the hydroxyl groups on the electrode surface, which is illustrated in reaction $\mathrm{R} 2$. This is supported by enhanced heterogeneous gelation (i.e. gel formation onto a solid surface) in comparison to homogeneous polymerization, which was notably exploited in the first example of mesoporous silica film deposition ${ }^{35}$. It should be stressed that both reactions R2 and R3 take place in parallel through the electrochemically-assisted deposition process. Before $t^{F}$, the film growth is mainly governed by $\mathrm{R} 2$, while after $t^{F} \mathrm{R} 3$ becomes dominant for the film thickness and $\mathrm{R} 2$ mainly contributes to the adhesion of the films. Here we will only briefly deal with the kinetics of R2 in the initial stage of the electrochemically-assisted deposition.

The reaction rate of $\mathrm{R} 2$, in terms of the variation in film thickness, can be expressed as:

$\frac{d l}{d t}=\frac{M_{\text {film }}}{\rho_{\text {film }}} k_{a} \Theta_{\text {Surf-OH }} C_{-S i O H}^{S}$

where $M_{\text {film }}$ and $\rho_{\text {film }}$ are the molecular weight of the condensation unit (e.g. $64 \mathrm{~g} \cdot \mathrm{mol}^{-1}$ for pure silica films) and the density of the film, respectively. $\Theta_{S u r f-O H}$ is the content of hydroxyl groups on the surface, which is in the unit of surface concentration $\left(\mathrm{mol} \cdot \mathrm{m}^{-2}\right) \cdot C_{-S i O H}^{S}$ is the concentration of the silanol groups near the electrode surface. $k_{a}$ is the heterogeneous rate constant. Since the surface concentration of hydroxyl groups is introduced, $k_{a}$ has unit of $\mathrm{m}^{3} \cdot \mathrm{mol}^{-1} \cdot \mathrm{s}^{-1}$ which is the same as $k_{f}$ in $E q$. 7. This might 
allow the comparison of the two values in future. The heterogeneous deposition occurs mainly at the initial stage of the film deposition, so the film is very thin and consumes little content of silanol. Thus the diffusion of silanol can be neglected and the concentration of silanol at the electrode surface equals to that in the bulk:

$C_{-S i O H}^{S}=C_{-S i O H}^{*}$

Similar as in homogeneous condensation, the rate constant $k_{a}$ can be expressed as a function of the concentration of $\mathrm{OH}^{-}$ions near the electrode surface $C_{O H^{-}}^{S}$ :

$k_{a}=k_{a}^{0}+k_{a}^{\prime} C_{O H^{-}}^{S} \approx k_{a}^{\prime} C_{O H^{-}}^{S}$

in which $k_{a}^{0}$ represents the rate constant without catalyst. It is negligible when the solution is stable and the sol-gel film grows on the electrode only by applying potential or current. Substituting Eq. 23 with Eq. 25:

$\frac{d l}{d t}=\frac{M_{\text {film }}}{\rho_{\text {film }}} \Theta_{\text {Surf }-\mathrm{OH}} C_{-\mathrm{SiOH}}^{*} k_{a}^{\prime} C_{O H^{-}}^{S}$

In Eq. 26, besides $C_{\mathrm{OH}^{-}}$which is governed by the electrochemical conditions, we leave with only one non-constant parameter $\Theta_{\text {Surf-OH }}$. The evolution of $\Theta_{\text {Surf-OH }}$ is very complicated, since the "surface" keeps changing due to the film formation. On one hand, the condensation may consume the available hydroxyl groups on the electrode surface, while on the other hand the adsorbed silane molecules may provide extra hydroxyl groups ( $-\mathrm{SiOH}$ groups that are attached to the electrode surface) that are available for further reactions, especially when the silane molecule consists of multiple hydrolysable groups. At the same time, some $-\mathrm{SiOH}$ groups in the attached silane molecules may also react with each other via homogeneous reaction R3 just like in the solution. As a result, it is very difficult to derive an exact expression that can take all these effects into consideration. Here, we will proceed by approximately assuming $\Theta_{\text {Surf-OH }}$ as constant. This assumption allows solving the Eq. 26.

In the initial stage of film deposition, the deposited film is very thin thus is unlikely to significantly affect the mass transport of $\mathrm{OH}^{-}$ions. Therefore $C_{O H^{-}}^{S}$ can be further substituted by the concentration of $\mathrm{OH}^{-}$ ions at $x=0$ as obtained from Eq. 6: 
$\frac{d l}{d t}=\frac{2 M_{\text {film }} \Theta_{\text {Surf-OH }} C_{-S i O H}^{*} k_{a}^{\prime} I_{F}}{\rho_{\text {film }} n F A D_{O H^{-}}} \sqrt{\frac{D_{O H^{-}}}{\pi}}$

With the initial condition $l=0$ at $t=0$, the thickness of the film as a function of time can be solved:

$l=\frac{4 M_{\text {film }} \Theta_{\text {Surf }-O H} C_{-S i O H}^{*} k_{a}^{\prime} I_{F}}{3 \rho_{\text {film }} n F A \sqrt{\pi D_{O H}}} t^{\frac{3}{2}}$

Eq. 28 shows that the thickness of the electrochemically-assisted deposited sol-gel film may be

proportional to $t^{\frac{3}{2}}$ when having only the heterogeneous adsorption. This could be applicable for describing the kinetics of film formation at the initial stage of electrochemically-assisted deposition before the silanol molecules aggregate in the solution via homogeneous condensation.

\subsection{Analysis of experimental data}

From the previous section, analytical expressions were derived for establishing quantitative relationship between the thickness of the electrochemically-assisted deposited sol-gel films and the experimental and kinetic parameters. The beauty of explicit analytical equations is that it is convenient for fitting the experimental data and obtaining the value of kinetic parameters with clear physical meaning.

For homogeneous gelation, the most important parameter is $t^{F}$. Its value could be determined directly by in-situ monitoring the film growth, such as by EQCM. Moreover, by introducing $t^{F}$ in Eqs. 15 and 20, one can obtain the following relationship:

$\frac{4}{3 \sqrt{\pi}}\left(1+L^{2}\right) e^{-L^{2}}-\left(2 L+\frac{4}{3} L^{3}\right) \operatorname{erfc}(L)=\frac{4}{3 \sqrt{\pi}}\left(\frac{t^{F}}{t}\right)^{\frac{3}{2}}$

where $L=\frac{l}{2 \sqrt{D_{O H^{-t}}}}$

Eq. 29 has the same form for both fast and slow diffusion of $-\mathrm{SiOH}$, which describes the thickness of the film as a function of time with only two parameters $D_{\mathrm{OH}^{-}}$and $t^{F}$. Therefore, it can be used for deriving the values of $D_{O H^{-}}$and $t^{F}$ by fitting the plot of $t^{-\frac{3}{2}} v s . \frac{l}{\sqrt{t}}$. This indicates that $t^{F}$ can also be obtained from the film thickness at different deposition time, which is more useful and practical than EQCM. However, 
it should be noted that Eq. 29 is not always valid (although with acceptable error in some cases) when considering the diffusion of $-\mathrm{SiOH}$. This will be discussed later by numerical simulation.

From Eqs. 16 and 21, it is known that $t^{F}$ is proportional to $I_{F}{ }^{-\frac{2}{3}}$ which can be expressed as:

$t^{F}=B I_{F}{ }^{-\frac{2}{3}}$

It can be used for validating the theory by linear fitting of $t^{F} v s . I_{F}{ }^{-\frac{2}{3}}$. The slope $B$ depends on the parameters $D_{\mathrm{OH}^{-}}, C_{-S i O H}^{*}, k_{f}^{\prime}$ and $C_{-S i O-}^{F}$. For the same sol-gel system, these parameters should be constant, even though their exact values may not be accurately determined. Therefore, one can use $B$ as a characteristic parameter for comparing the electrochemically-assisted deposition kinetics in different solgel systems.

By substituting $t^{F}$ in $E q .29$ with $E q .30$, one can obtain the relationship between the film thickness and the Faraday current $I_{F}$ :

$\frac{4}{3 \sqrt{\pi}}\left(1+L^{2}\right) e^{-L^{2}}-\left(2 L+\frac{4}{3} L^{3}\right) \operatorname{erfc}(L)=\frac{4}{3 I_{F} \sqrt{\pi}}\left(\frac{B}{t}\right)^{\frac{3}{2}}$

Eq. 31 describes the quantitative relationship between the film thickness and the Faraday current for deposition. When studying the film thickness as a function of $I_{F}$, the deposition time $t$ is usually kept constant, thus the parameter $B$ can be fitted from $\frac{1}{I_{F}} v s . l$ using $E q .31$. This offers another practical approach for determining the value of kinetic parameters from experimental results.

For heterogeneous film formation, one may use Eq. 28 to fit the film thickness as a function of time. Nevertheless, special cautions should be noted. The derivation of Eq. 28 requires $\Theta_{\text {Surf-OH }}$ being constant, which is difficult to be fulfilled. In addition, the film thickness in heterogeneous-only deposition is usually very low (less than $100 \mathrm{~nm}$ ), thus may have high experimental error. Eq. 28 is valid only before $t^{F}$. When $t^{F}$ is low, it can only be applied in a narrow time window, then it is very difficult to accurately control the deposition time in practice. Therefore, it is recommended to use Eq. 28 only as a semiquantitative tool for explaining the experimental data. 


\section{Validation of the theory}

The validation of the theory developed above is achieved in two directions. One direction is by numerical simulation. We purposely simulate the cases when the required approximations for the theory are not fulfilled, and examine the applicability and error of the theory. Another direction is by experimental data. We examine the applicability of the theory by confrontation to experimental data published by different research groups. It should be noted that we only validated the theory for homogeneous gelation. The kinetics of heterogeneous film formation is not yet covered due to the unclear parameter $C_{S u r f-O H}$ and the lack of reliable experimental data.

\subsection{Validation of the approximations by simulation}

The derivation of equations above for homogeneous film deposition was based on two major approximations:

(1) The film formation does not change the diffusion coefficient of $\mathrm{OH}^{-}$and $-\mathrm{SiOH}$.

(2) The diffusion of $-\mathrm{SiOH}$ is either very fast or very slow, that is, $D_{-\mathrm{SiOH}}=0$ or $C_{-\mathrm{SiOH}}=C_{-\mathrm{SiOH}}^{*}$.

However, in practice these two approximations could not always be fulfilled. Considering the diffusion of $-\mathrm{SiOH}$ and different diffusion coefficients of $\mathrm{OH}^{-}$and $-\mathrm{SiOH}$ in the deposited film, one has to deal with Eqs. 1 and 8 by different coefficients at $x<l$ and $x>l$. The film thickness $l$ also changes as the film grows, and the boundary condition for $\mathrm{OH}^{-}$generation changes at $t^{F}$. It is impossible to obtain explicit solutions for such complicated system, thus we seek for numerical simulation by finite element method. The latter is a powerful tool for dealing with the kinetics of complicated systems ${ }^{36,37}$. It has been widely used in electrochemistry, such as the simulation of CV curves $^{38}$.

The numerical simulation was programmed by Fortran 95. The equations for simulation, the source code and the compiled program are attached in the Supporting Information. A set of common parameters and constants for simulation is listed in Tab. 1. The values of these parameters are estimated according to experimental results ${ }^{24}$. The simulation results are used for examining the validity of the analytical 
solutions. It should be noted that the results are discussed directly with the parameters in an explicit way for the easier understanding by experimentalists, even though dimensionless parameters were actually used in programming.

Tab. 1 Common parameters and constants for simulation of electrochemically-assisted deposition of silane films via homogeneous condensation.

\begin{tabular}{cc}
\hline Parameters & Value \\
$n$ & 1 \\
$F$ & $96485 \mathrm{C} \cdot \mathrm{mol}^{-1}$ \\
$A$ & $1 \mathrm{~cm}^{2}$ \\
$I_{F}$ & $0.159 \mathrm{~A}$ \\
$D_{O H^{-}}$ & $9.3 \times 10^{-5} \mathrm{~cm}^{2} \cdot \mathrm{s}^{-1}$ \\
$C_{-S i O-}^{F}$ & $3.0 \times 10^{-5} \mathrm{~mol}^{-\mathrm{cm}^{-3}}$ \\
$k_{f}^{\prime}$ & $1.185 \times 10^{6} \mathrm{~cm}^{6} \cdot \mathrm{mol}^{-2} \cdot \mathrm{s}^{-1}$
\end{tabular}

The first step is to examine the effect of $D_{-S i O H}$. This was carried out by assuming $D_{O H^{-}}^{f i l m}=D_{O H^{-}}^{\text {sol and }}$ $D_{-S i O H}^{f i l m}=D_{-S i O H}^{\text {SOl }}$. Fig. 1 compares the simulation results with the parameters in Tab. $\mathbf{1}$ and different $D_{-S i O H}$ values in the solution with low concentration of silanol precursor $\left(C_{-S i O H}^{*}=5.44 \times 10^{-5} \mathrm{~mol}\right.$. $\mathrm{cm}^{-3}$, comparable with $C_{-S i O_{-}}^{F}$ ). The $t^{F}$ value calculated from $E q .16$ (48.0 s) is significantly different from that calculated from $E q .21\left(81.9\right.$ s). By considering the diffusion of $-\mathrm{SiOH}$, the $t^{F}$ as seen from the simulated results fall between $48.0 \mathrm{~s}$ and $81.9 \mathrm{~s}$, indicating that the relationship Eq. 22 is valid. As the value of $D_{-S i O H}$ increases, the $t^{F}$ decreases. Moreover, the simulated film thickness is close to the analytical curve for $D_{-S i O H}=0$ for reasonable $D_{-S i O H}$ values. We would like to remind that the diffusion of $-\mathrm{SiOH}$ groups is governed by the diffusion of both hydrolyzed silanol precursor towards the electrode and condensed oligomers (which may still contain high content of $-\mathrm{SiOH}$ groups) away from the electrode. Thus $D_{-S i O H}$ is unlikely to be higher than the diffusion coefficient for most of the ions in the aqueous solution $\left(2 \times 10^{-5} \mathrm{~cm}^{2} \cdot \mathrm{s}^{-1}\right)$. This indicates that $D_{-S i O H}=0$ is a better approximation than $C_{-S i O H}=$ 
$C_{-S i O H}^{*}$. Simulation was also carried out for $D_{-S i O H}=0$ and the results were identical to that calculated from analytical expressions Eqs. 20 and 21. This confirms that the simulation is correct.

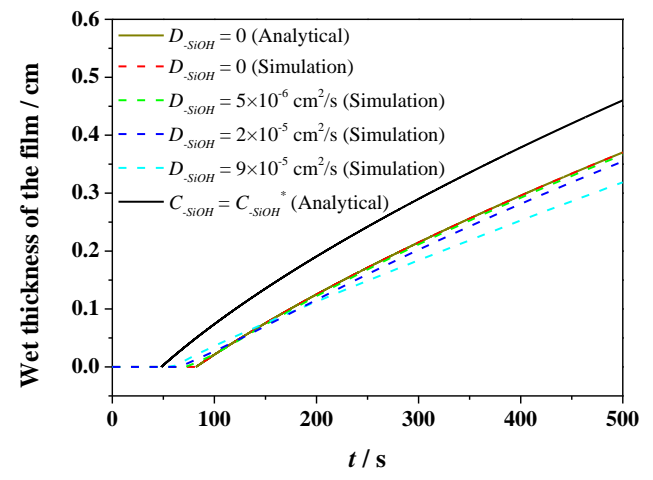

Fig. 1 Analytical and simulation results for different $D_{-S i O H}$ values when $C_{-S i O H}^{*}=5.44 \times 10^{-5} \mathrm{~mol}$.

$$
\mathrm{cm}^{-3}
$$

When $C_{-S i O H}^{*}\left(5.44 \times 10^{-4} \mathrm{~mol} \cdot \mathrm{cm}^{-3}\right)$ is much higher than $C_{-S i O-}^{F}$, the $t^{F}$ value calculated from $E q .16(2.23$ s) is very close to that calculated from Eq. 21 (2.31 s). In this case, both equations can be used. The simulation results with different $D_{-S i O H}$ values also almost overlap with the analytical results (Fig. 2). From the results above, it is seen that when $C_{-S i O H}^{*}$ is comparable with $C_{-S i O-}^{F}$, the approximation $D_{-S i O H}=0$ is better than the approximation $C_{-S i O H}=C_{-S i O H}^{*}$. When $C_{-S i O H}^{*} \gg C_{-S i O-}^{F}$, both approximations can be used.

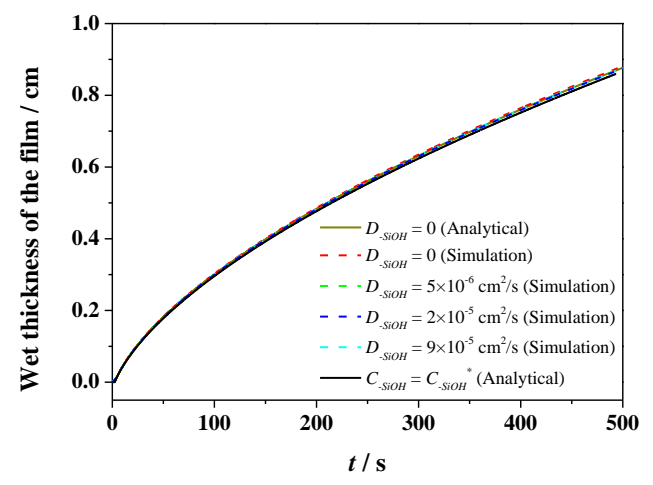


Fig. 2 Analytical and simulation results for different $D_{-S i O H}$ values when $C_{-S i O H}^{*}=5.44 \times 10^{-4} \mathrm{~mol}$.

$$
\mathrm{cm}^{-3} \text {. }
$$

The second step is to further simulate the more general case in which the diffusion of species is hindered by the deposited film. The diffusion coefficient of species is expected to be lower in a gel than in an aqueous solution. This would affect the kinetics of film formation and challenge the validity of Eqs. 5 and 6 which is the basis of all theoretical derivations in this work. Here, we assume the diffusion coefficients in the solution $D_{\mathrm{OH}^{-}}=9.3 \times 10^{-5} \mathrm{~cm}^{2} \cdot \mathrm{s}^{-1}$ and $D_{-\mathrm{SiOH}}=2.0 \times 10^{-5} \mathrm{~cm}^{2} \cdot \mathrm{s}^{-1}$. The diffusion coefficients in the film were defined by multiplying a factor to the diffusion coefficients in the solution, for both $\mathrm{OH}^{-}$and $-\mathrm{SiOH}$. The factor is denoted as $D^{\text {film }} / D^{\text {sol }}$. The simulation results are shown in Fig. 3. It is seen that for both high and low $C_{-S i O H}^{*}$, the film thickness decreases as $D^{\text {film }} / D^{\text {sol }}$ decreases. However, the onset time for film formation $t^{F}$ is not affected by the ratio $D^{\text {film }} / D^{\text {sol }}$, because before film formation the kinetics of film deposition is only affected by the diffusion coefficients in the solution.
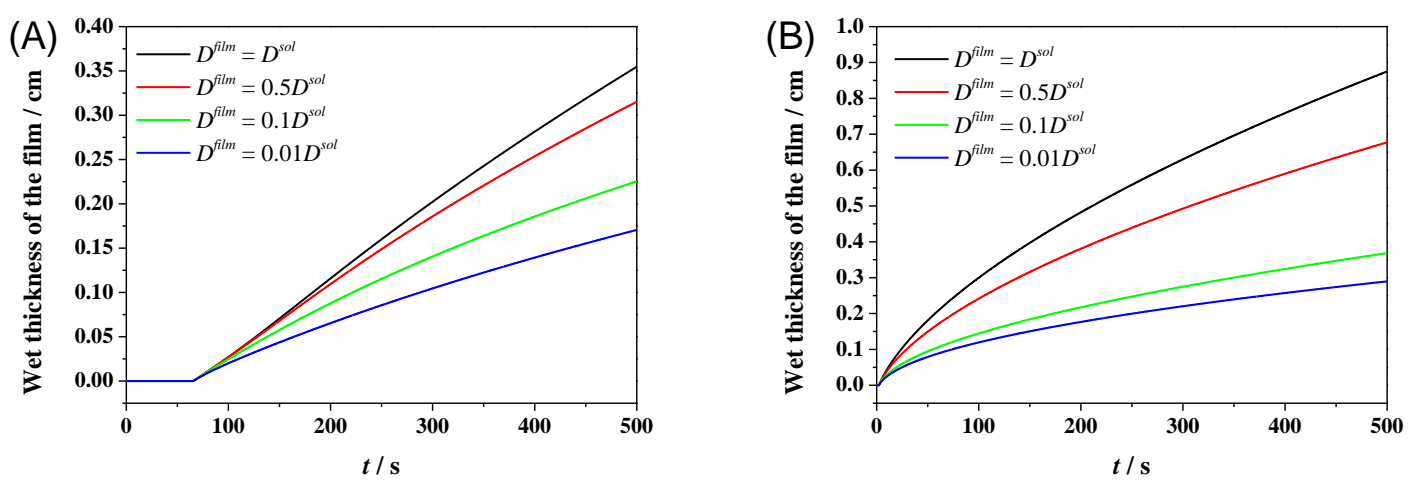

Fig. 3 Simulation results for different values of $D^{f i m} / D^{s o l}$ with $D_{O H^{-}}=9.3 \times 10^{-5} \mathrm{~cm}^{2} \cdot \mathrm{s}^{-1}$ and $D_{-S i O H}=$ $2.0 \times 10^{-5} \mathrm{~cm}^{2} \cdot \mathrm{s}^{-1} \cdot C_{-S i O H}^{*}=5.44 \times 10^{-5} \mathrm{~mol} \cdot \mathrm{cm}^{-3}(\mathrm{~A})$ and $C_{-S i O H}^{*}=5.44 \times 10^{-4} \mathrm{~mol} \cdot \mathrm{cm}^{-3}(\mathrm{~B})$.

As discussed in Section 2.3, an effective method to derive $t^{F}$ is fitting the film thickness as a function of time by $E q .29$, particularly in the form of $t^{-\frac{3}{2}} v s \cdot \frac{l}{\sqrt{t}}$. Thus, we further examined the validity of $E q .29$ by 
the simulation results above. Fig. 4 shows the fitting of simulated results obtained at $D^{\text {fimm }} / D^{\text {sol }}=0.1$ with $D_{O H^{-}}=9.3 \times 10^{-5} \mathrm{~cm}^{2} \cdot \mathrm{s}^{-1}, D_{-\mathrm{SiOH}}=2.0 \times 10^{-5} \mathrm{~cm}^{2} \cdot \mathrm{s}^{-1}$. For $C_{-\mathrm{SiOH}}^{*}=5.44 \times 10^{-5} \mathrm{~mol} \cdot \mathrm{cm}^{-3}$, the simulation results can be well fitted by Eq. 29. The fitted $t^{F}$ value is $65.6 \mathrm{~s}$, which is almost the same as seen from simulation results. However, the fitted $D_{O H^{-}}$is $2.99 \times 10^{-5} \mathrm{~cm}^{2} \cdot \mathrm{s}^{-1}$, which is much lower than the input value. For $C_{-S i O H}^{*}=5.44 \times 10^{-4} \mathrm{~mol} \cdot \mathrm{cm}^{-3}$, the values of $t^{F}$ and $D_{O H^{-}}$could still be fitted, but the fitted curve does not overlap well with the simulation results. The fitted $t^{F}$ is $2.023 \pm 0.005 \mathrm{~s}$, which has $c a .10 \%$ error as compared with the value calculated by analytical expressions Eqs. 16 and 21 . The fitted apparent $D_{\mathrm{OH}^{-}}$is $2.93 \times 10^{-5} \mathrm{~cm}^{2} \cdot \mathrm{s}^{-1}$. It is also much lower than the input value but similar to that fitted from the solution with high concentration of $-\mathrm{SiOH}$.
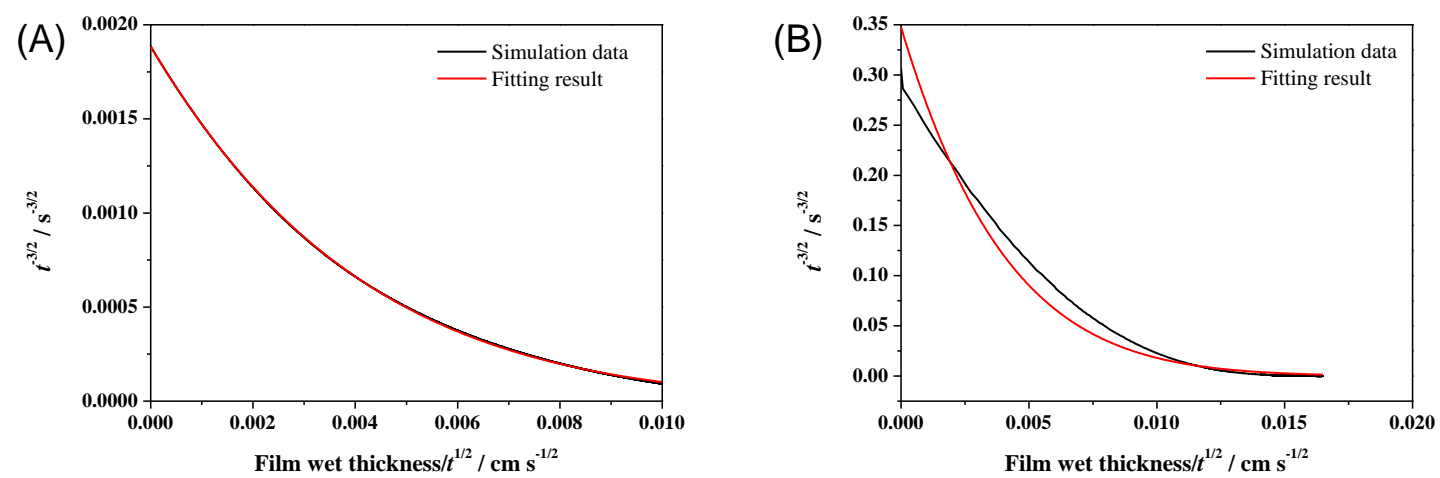

Fig. 4 Simulation data and fitted result for $D_{-S i O H}=2.0 \times 10^{-5} \mathrm{~cm}^{2} \cdot \mathrm{s}^{-1}, D^{\text {film }} / D^{\text {sol }}=0.1 . C_{-S i O H}^{*}=$

$$
5.44 \times 10^{-5} \mathrm{~mol} \cdot \mathrm{cm}^{-3}(\mathrm{~A}) \text { and } C_{-S i O H}^{*}=5.44 \times 10^{-4} \mathrm{~mol} \cdot \mathrm{cm}^{-3}(\mathrm{~B}) .
$$

From the results above, one can see that Eq. 29 is not strictly valid when considering the diffusion of $\mathrm{SiOH}$ with a reasonable value of diffusion coefficient $\left(D_{-\mathrm{SiOH}}=2.0 \times 10^{-5} \mathrm{~cm}^{2} \cdot \mathrm{s}^{-1}\right)$ and the reduced

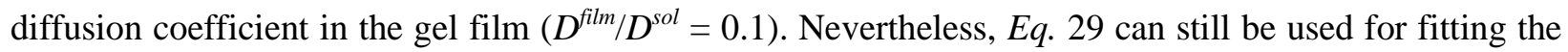
results getting the approximate value of $t^{F}$. The fitted $t^{F}$ with reasonable error $(c a .10 \%)$ can further be used for estimating the kinetic parameter $k_{f}^{\prime}$ by Eqs. 16 and 21. The fitted $D_{O H^{-}}$has an apparent value between the diffusion coefficient of $\mathrm{OH}^{-}$in the solution and that in the film. Qualitatively, it reflects the 
"convoluted" diffusion behavior in the solution and in the film. The physical meaning of its quantitative value is still yet to be explored.

\subsection{Validation of the theory by experimental data}

The most convincing way of validating a theory is by experimental data. In the past decade, many researchers have developed and investigated the electrochemically-assisted sol-gel deposition method ${ }^{13,14}$ 23, 28, 39-41. Most of these works were carried out by controlling the potential. Generally, during the deposition, the current response initially decreased due to the charging of double layer, and afterwards did not significantly change ${ }^{24}$. Therefore, the Faraday current could be approximately considered as constant, which fulfills the pre-assumption of the theoretical framework.

In literature ${ }^{24}, t^{F}$ was determined from EQCM results (for the particular case of surfactant-templated mesoporous silica films). Fig. 5 shows the fitting of $t^{F}$ as a function of $I_{F}{ }^{-\frac{2}{3}}$. The linearity is acceptable, although the number of points in experiments was insufficient. This could support $E q$. 30, which indicates that $t^{F}$ is proportional to $I_{F}{ }^{-\frac{2}{3}}$. From the slope, one may calculate the value of the kinetic parameter $k_{f}{ }^{\prime}$ by estimating the critical concentration of condensed silanol group for gelation $\left(C_{-S i O-}^{F}\right)$ in Eqs. 16 and 21. It should be noted that Eq. 30 requires further verifications by more systematic experimental results in future.

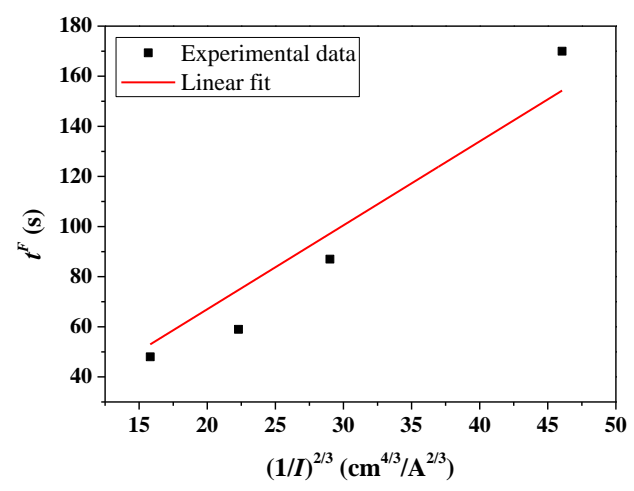


Fig. 5 Experimental data from E. Sibottier, S. Sayen, F. Gaboriaud, A. Walcarius, Langmuir, 22 (2006) $8366^{24} . t^{F}$ was read from Fig. 3A and $I$ was read from the steady state current in Fig. A in supporting information.

A more interesting approach is to determine $t^{F}$ from the film thickness at different deposition time by fitting with $E q$. 29. It should be noted that in the theoretical framework, the thickness $l$ refers to the wet thickness of the gel, which must be measured in-situ and is very difficult to be accurately determined ${ }^{42}$. In experimental works, the film thickness usually refers to the dry thickness, which was measured after curing of the film. The dry thickness is much less than the wet thickness due to the shrinking of the film by evaporation of the solvent ${ }^{43}$. If the solid content and density of the film does not change upon film growth, the wet thickness should be proportional to the dry thickness and the normalized thickness $\mathrm{L}$ in Eq. 29 can be expressed as:

$L=\frac{l}{2 \sqrt{D_{O H^{-}}}}=N \frac{l_{d r y}}{2 \sqrt{D_{O H^{-}}}}$

where $N$ is a factor related to the solid content and density of the gel films and $l_{d r y}$ is the dry thickness of the film. For example, if the cured film contains only $\mathrm{SiO}_{2}$, and the concentration of $\mathrm{SiO}_{2}$ in the wet gel film equals to that in the sol precursor, $N$ can be expressed as follows:

$N=\frac{\rho_{\text {film }}}{M_{\mathrm{SiO}_{2}} C_{S i}^{*}}$

where $\rho_{\text {film }}$ is the density of the dry film, $M_{\mathrm{SiO}_{2}}$ is the molecular weight of $\mathrm{SiO}_{2}$ and equals to $60 \mathrm{~g} / \mathrm{mol}$, $C_{S i}^{*}$ is the molar concentration of silane monomer in the solution (in $\mathrm{Si}$ ). The density of the dry film depends on the porosity. By non-linear fitting $t^{-\frac{3}{2}}$ vs. $\frac{l}{\sqrt{t}}$ by $E q .29$, one can obtain the values of $t^{F}$ and $\frac{N}{2 \sqrt{D_{O H^{-}}}}$. Fig. 6 shows that Eq. 29 could well fit the film thickness as a function of time for the electrochemically-assisted deposition of TEOS silane films. The fitted $t^{F}$ is $1.3 \pm 0.3 \mathrm{~s}$ and $\frac{N}{2 \sqrt{D_{O H^{-}}}}$is $(2.68 \pm 0.19) \times 10^{4} \mathrm{~cm}^{-1} \cdot \mathrm{s}^{1 / 2}$. In another experimental work which involves the electrochemically-assisted 
deposition of sol-gel films with carbon nanotubes, the thickness as a function of time could also be well fitted by Eq. 29 as shown in Fig. 7.

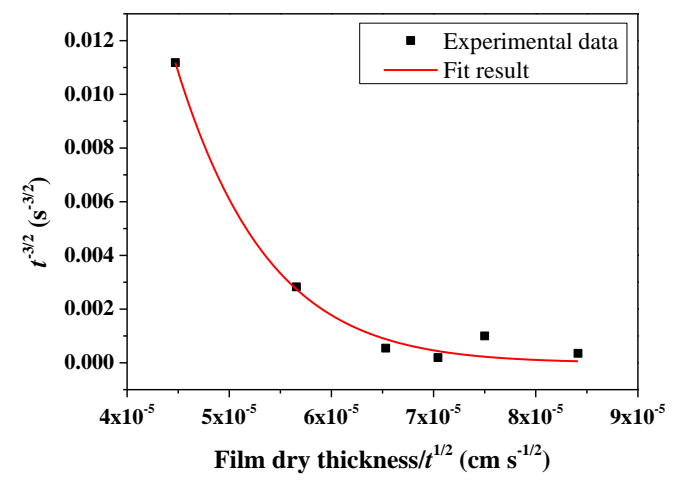

Fig. 6 Experimental data from L.K. Wu, J.M. Hu, J.Q. Zhang, C.N. Cao, Electrochem. Commun. 26 (2013) $85^{23}$. Data read from Fig. 2A.

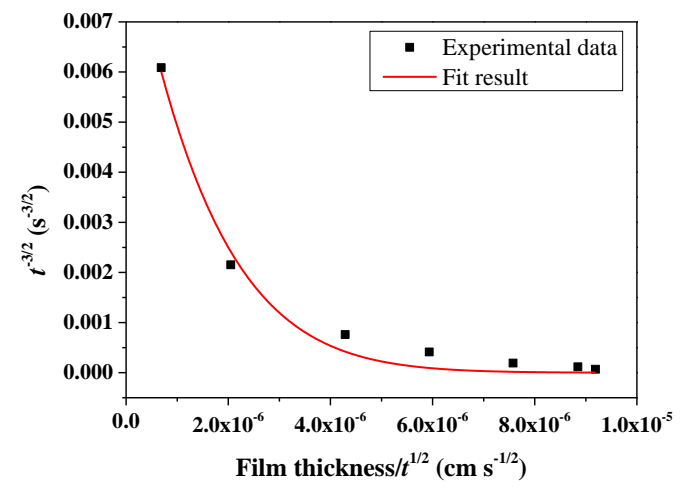

Fig. 7 Fitting of experimental data from L. Liu, S. Yellinek, N. Tal, R. Toledano, A. Donval, D. Yadlovker, D. Mandler, J. Mater. Chem. C, 3 (2015) 10994. Data read from Fig. 3A.

From fitted $t^{F}$ and $\frac{N}{2 \sqrt{D_{O H^{-}}}}$values, one can estimate the kinetic parameter $k_{f}^{\prime}$ if $C_{-S i O_{-}}^{F}$ is known, and the value $N$ if $D_{O H^{-}}$is known. From $N$, one can further calculate the density of the film $\rho_{\text {film }}$, and then the porosity of the film could be obtained. In Fig. 6, the fitted $N$ value is 516.9 if considering $D_{\mathrm{OH}^{-}}$as $9.3 \times$ $10^{-5} \mathrm{~cm}^{2} / \mathrm{s}$. This is much higher than the calculated value from $E q .33$ (159.1, taking $M_{\mathrm{SiO}_{2}}$ as $60 \mathrm{~g} / \mathrm{mol}$, $\rho_{\text {film }}$ as $2.196 \mathrm{~g} / \mathrm{cm}^{3}$ for amorphous silica and $C_{S i}^{*}$ as $0.23 \mathrm{~mol} / \mathrm{L}$ from experimental conditions ${ }^{23}$ ). It can 
be explained by two possible reasons: (1) the explicit value of $D_{O H^{-}}$is lower than the diffusion coefficient of $\mathrm{OH}^{-}$in the solution due to the inhibition of diffusion in the gel film. For the simulation results, its apparent value could be fitted but the physical meaning is still unclear; (2) in experimental work the wet gel film might be partially removed before curing due to the poor cohesion. The former lead to the difficulty in quantitatively determining the value of $N$, and the latter would challenge the applicability of

Eq. 33. Therefore we do not recommend to elaborate too much from the parameter $\frac{N}{2 \sqrt{D_{O H^{-}}}}$, and in-situ monitoring the thickness of the wet gel film during the electrochemically-assisted deposition shall be carried out for better validating the theory in future.

\section{Conclusions}

In conclusion, a preliminary quantitative kinetic model is built up for quantitatively describing the growth of sol-gel films generated by electrochemically-assisted deposition. Initially, the film mainly deposits via heterogeneous adsorption of silanol moieties of the precursor condensing with the hydroxyl groups present on the electrode surface. At the same time the silanol moieties of the precursor in the solution undergoes condensation forming oligomers. Once the degree of polymerization on the electrode reaches the gelation point, the film thickness significantly increases due to the homogeneous gelation of the precursors. Analytical expressions are derived for both routes under approximations that the diffusion of silanol group is either very fast or very slow and the film formation does not affect the diffusion of $\mathrm{OH}^{-}$ and $-\mathrm{SiOH}$. Numerical simulation shows that the equations derived for homogeneous deposition are still valid with acceptable error in reasonable cases when the approximations are not fulfilled. The validity of the equations Eqs. 29 and 30 for homogeneous deposition was further examined by experimental results. This theoretical model developed here explains well the experimental phenomena reported in literature and provides a semi-quantitative method for determining kinetic parameters for the electrochemicallyassisted deposition of sol-gel films. The applicability of the results could further be expanded to other similar indirect electrodeposition systems which are driven by electrochemically generated catalysts. 


\section{Nomenclature}

\begin{tabular}{|c|c|c|}
\hline Symbol & SI unit & Physical meaning \\
\hline$C_{O H^{-}}, C_{O H^{-}}^{*}, C_{O H^{-}}^{S}$ & $\mathrm{~mol} \cdot \mathrm{m}^{-3}$ & Concentration of $\mathrm{OH}^{-},{ }^{*}$ bulk solution, ${ }^{s}$ electrode surface \\
\hline$C_{-\mathrm{SiOH}}, C_{-\mathrm{SiOH}}^{*}, C_{-\mathrm{SiOH}}^{S}$ & $\mathrm{~mol} \cdot \mathrm{m}^{-3}$ & Concentration of silanol group \\
\hline$C_{-S i O-}, C_{-S i O-}^{F}$ & $\mathrm{~mol} \cdot \mathrm{m}^{-3}$ & Concentration of condensed silanol group, ${ }^{F}$ gelation point \\
\hline & $\mathrm{mol} \cdot \mathrm{m}^{-3}$ & Concentration of $\mathrm{Si}$ in the bulk solution \\
\hline$\Theta_{\text {Surf-OH }}$ & $\mathrm{mol} \cdot \mathrm{m}^{-2}$ & Surface coverage of hydroxyl group on the electrode surface \\
\hline$D_{O H^{-}}, D_{O H^{-}}^{\text {sol }}, D_{O H^{-}}^{f i l m}$ & $\mathrm{~m}^{2} \cdot \mathrm{s}^{-1}$ & Diffusion coefficient of $\mathrm{OH}^{-},{ }^{\text {sol }}$ solution, ${ }^{\text {film }}$ gel film \\
\hline$D_{-\mathrm{SiOH}}, D_{-\mathrm{SiOH}}^{\mathrm{SOl}}, D_{-\mathrm{SiOH}}^{\text {film }}$ & $\mathrm{m}^{2} \cdot \mathrm{s}^{-1}$ & Diffusion coefficient of silanol group \\
\hline$k_{f}, k_{f}^{0}$ & $\mathrm{~m}^{3} \cdot \mathrm{mol}^{-1} \cdot \mathrm{s}^{-1}$ & $\begin{array}{l}\text { Homogeneous reaction rate constant for the condensation of } \\
\text { silanol groups, reaction order } 2,{ }^{0} \text { refers to no catalytic effect }\end{array}$ \\
\hline$k_{f}^{\prime}$ & $\mathrm{m}^{6} \cdot \mathrm{mol}^{-2} \cdot \mathrm{s}^{-1}$ & $\begin{array}{l}\text { Reaction rate constant for the catalytic effect of } \mathrm{OH}^{-} \text {on the } \\
\text { homogeneous condensation }\end{array}$ \\
\hline$k_{a}, k_{a}^{0}$ & $\mathrm{~m}^{3} \cdot \mathrm{mol}^{-1} \cdot \mathrm{s}^{-1}$ & $\begin{array}{l}\text { Heterogeneous reaction rate constant for silanol adsorption on } \\
\text { the electrode surface }\end{array}$ \\
\hline$k_{a}^{\prime}$ & $\mathrm{m}^{6} \cdot \mathrm{mol}^{-2} \cdot \mathrm{s}^{-1}$ & $\begin{array}{l}\text { Reaction rate constant for the catalytic effect of } \mathrm{OH}^{-} \text {on the } \\
\text { heterogeneous adsorption of silanol }\end{array}$ \\
\hline$X$ & 1 & Dimensionless parameter $X=\frac{x}{2 \sqrt{D_{O H^{-}}}}$ \\
\hline$l$ & $\mathrm{~m}$ & Wet thickness of the gel film \\
\hline$l_{d r y}$ & $\mathrm{~m}$ & Dry thickness of the gel film \\
\hline$L$ & 1 & Dimensionless parameter $L=\frac{l}{2 \sqrt{D_{O H^{-}}}}$ \\
\hline$n$ & 1 & Number of electrons for generating $\mathrm{OH}^{-}, n=1$ \\
\hline$F$ & $\mathrm{C} \cdot \mathrm{mol}^{-1}$ & Faraday constant, $96485 \mathrm{C} \cdot \mathrm{mol}^{-1}$ \\
\hline$A$ & $\mathrm{~m}^{2}$ & Electrode area (By default $\left.1 \mathrm{~cm}^{2}\right)$ \\
\hline$I_{F}$ & A & Applied Faraday current \\
\hline$t^{F}$ & $\mathrm{~s}$ & Time required for initiating homogeneous deposition \\
\hline$M_{\text {film }}, M_{\mathrm{SiO}_{2}}$ & $\mathrm{~g} \cdot \mathrm{mol}^{-1}$ & Molar weight of the gel film, $\mathrm{SiO}_{2}$. \\
\hline$\rho_{\text {film }}$ & $\mathrm{g} \cdot \mathrm{m}^{-3}$ & Density of the gel film \\
\hline $\mathrm{B}$ & $\mathrm{s} \cdot \mathrm{A}^{2 / 3}$ & Convoluted kinetic parameter, slope of $t^{F}$ vs. $I_{F}{ }^{-\frac{2}{3}}$ \\
\hline $\mathrm{N}$ & 1 & Dimensionless factor $\frac{l}{l_{d r y}}$ \\
\hline
\end{tabular}

\section{References}

1. J. J. Ebelmen, Annales de Chimie et de Physique, 1846, 16, 129-166.

2. J. J. Ebelmen, Comptes Rendus de l'Academie des Sciences, 1847, 25, 854.

3. T. Graham, J. Chem. Soc., 1864, 17, 318-327.

4. C. J. Brinker and G. W. Scherer, in Sol-Gel Science, Academic Press, San Diego, 1990, DOI: http://dx.doi.org/10.1016/B978-0-08-057103-4.50019-2, pp. 838-880. 
5. R. Toledano and D. Mandler, Chem. Mater., 2010, 22, 3943-3951.

6. L. Liu, J. M. Hu, W. H. Leng, J. Q. Zhang and C. N. Cao, Scripta Mater, 2007, 57, 549-552.

7. D. Avnir, J. Blum and Z. Nairoukh, in The Sol-Gel Handbook, Wiley-VCH Verlag GmbH \& Co. KGaA, 2015, DOI: 10.1002/9783527670819.ch31, pp. 963-986.

8. I. Mazurenko, O. Tananaiko, O. Biloivan, M. Zhybak, I. Pelyak, V. Zaitsev, M. Etienne and A. Walcarius, Electroanalysis, 2015, 27, 1685-1692.

9. T. M. Harrell, B. Hosticka, M. E. Power, L. Cemke, R. Hull and P. M. Norris, J. Sol-Gel Sci. Technol., 2004, 31, 349-352.

10. C. J. Brinker, A. J. Hurd, P. R. Schunk, G. C. Frye and C. S. Ashley, J. Non-Cryst. Solids, 1992, 147-148, 424-436.

11. J. W. S.M.Attia, Guangming WU, Jun SHEN, Jianhua MA, J. Mater. Sci. Technol., 2002, 18, 211-217.

12. D. Grosso, C. Boissière and M. Faustini, in The Sol-Gel Handbook, Wiley-VCH Verlag GmbH \& Co. KGaA, 2015, DOI: 10.1002/9783527670819.ch09, pp. 277-316.

13. R. Shacham, D. Avnir and D. Mandler, Adv. Mater., 1999, 11, 384-388.

14. L. Liu and D. Mandler, in The Sol-Gel Handbook: Synthesis, Characterization and Applications, eds. D. Levy and Z. M., Wiley, 2015, vol. 1, ch. 12, pp. 373-414.

15. A. Walcarius, E. Sibottier, M. Etienne and J. Ghanbaja, Nat. Mater., 2007, 6, 602-608.

16. M. Etienne, A. Goux, E. Sibottier and A. Walcarius, J Nanosci. Nanotechnol., 2009, 9, 23982406.

17. A. Goux, M. Etienne, E. Aubert, C. Lecomte, J. Ghanbaja and A. Walcarius, Chem. Mater., 2009, 21, 731-741.

18. N. Vila, J. Ghanbaja, E. Aubert and A. Walcarius, Angew Chem Int Edit, 2014, 53, 2945-2950.

19. N. Vilà and A. Walcarius, Electrochim. Acta, 2015, 179, 304-314.

20. V. Urbanová, M. Etienne and A. Walcarius, Electroanalysis, 2013, 25, 85-93.

21. J. M. Hu, L. Liu, J. Q. Zhang and C. N. Cao, Prog. Org. Coat., 2007, 58, 265-271. 
22. L. Liu and D. Mandler, in Handbook of Sol-Gel Science and Technology, eds. L. Klein, M. Aparicio and A. Jitianu, Springer International Publishing, 2 edn., 2018.

23. L. K. Wu, J. M. Hu, J. Q. Zhang and C. N. Cao, Electrochem. Commun., 2013, 26, 85-88.

24. E. Sibottier, S. Sayen, F. Gaboriaud and A. Walcarius, Langmuir, 2006, 22, 8366-8373.

25. F. Qu, R. Nasraoui, M. Etienne, Y. B. S. Côme, A. Kuhn, J. Lenz, J. Gajdzik, R. Hempelmann and A. Walcarius, Electrochem. Commun., 2011, 13, 138-142.

26. L. L. Jiang, L. K. Wu, J. M. Hu, J. Q. Zhang and C. N. Cao, Corros. Sci, 2012, 60, 309-313.

27. S. Z. Ding, L. Liu, J. M. Hu, J. Q. Zhang and C. N. Cao, Scr. Mater., 2008, 59, 297-300.

28. M. M. Collinson, D. A. Higgins, R. Kommidi and D. Campbell-Rance, Anal. Chem., 2008, 80, 651-656.

29. Y.-Q. Yang, L. Liu, J.-M. Hu, J.-Q. Zhang and C.-N. Cao, Thin Solid Films, 2012, 520, 20522059.

30. L. Liu, R. Toledano, T. Danieli, J. Q. Zhang, J. M. Hu and D. Mandler, Chem. Commun., 2011, 47, 6909-6911.

31. F. D. Osterholtz and E. R. Pohl, J. Adhes. Sci. Technol., 1992, 6, 127-149.

32. E. P. Plueddemann, Silane Coupling Agents, Springer, 2nd edn., 1991.

33. C. J. Brinker and G. W. Scherer, in Sol-Gel Science, Academic Press, San Diego, 1990, DOI: http://dx.doi.org/10.1016/B978-0-08-057103-4.50010-6, pp. 302-355.

34. A. J. Bard and L. R. Faulkner, Electrochemical Methods: Fundamentals and Applications, Wiley, 2 edn., 2001.

35. H. Yang, A. Kuperman, N. Coombs, S. Mamiche-Afara and G. A. Ozin, Nature, 1996, 379, 703705.

36. P. Mandin, J. M. Cense, C. Fabian, C. Gbado and D. Lincot, Computers \& Chemical Engineering, 2007, 31, 980-992.

37. P. Mandin, J. M. Cense, G. Picard and D. Lincot, Electrochim. Acta, 2006, 52, 1296-1308. 
38. R. G. Compton, C. Batchelor-Mcauley and E. J. F. Dickinson, Understanding Voltammetry: Simulation of Electrode Processes, Imperial College Press, 2014.

39. J. Niedziolka and M. Opallo, Electrochem. Commun., 2008, 10, 1445-1447.

40. M. M. Collinson, Acc. Chem. Res., 2007, 40, 777-783.

41. A. Walcarius, D. Mandler, J. A. Cox, M. Collinson and O. Lev, J. Mater. Chem., 2005, 15, 3663.

42. Y. Cheng, X. Luo, J. Betz, S. Buckhout-White, O. Bekdash, G. F. Payne, W. E. Bentley and G. W. Rubloff, Soft Matter, 2010, 6, 3177-3183.

43. C. Song and G. Villemure, Microporous Mesoporous Mater., 2001, 44-45, 679-689.

44. L. Liu, S. Yellinek, N. Tal, R. Toledano, A. Donval, D. Yadlovker and D. Mandler, Journal of Materials Chemistry C, 2015, 3, 1099-1105. 


\title{
Kinetics of the electrochemically-assisted deposition of sol-gel films
}

\author{
Liang Liu*, Alain Walcarius \\ Laboratoire de Chimie Physique et Microbiologie pour l'Environnement, UMR 7564, CNRS-Université \\ de Lorraine, 405 rue de Vandoeuvre, 54600 Villers-lès-Nancy, France \\ *Email: liang.liu@univ-lorraine.fr

\section{Supporting Information}

\section{Description of the numerical simulation}

By dividing the concerned length and time into small segments $\Delta x$ and $\Delta t$, respectively, the film deposition process can be expressed in numerical form. At $\mathrm{x}=0$, the concentration of $\mathrm{OH}^{-}$ions is affected by the flux of electrochemical generation and the diffusion:

$$
\begin{aligned}
& \mathrm{C}_{\mathrm{OH}^{-}}(0, \mathrm{t}+\Delta \mathrm{t})=\mathrm{C}_{\mathrm{OH}^{-}}(0, \mathrm{t})+\frac{\Delta \mathrm{t}}{\Delta \mathrm{x}^{2}} \mathrm{D}_{\mathrm{OH}^{-}}^{\mathrm{sol}}\left(\mathrm{C}_{\mathrm{OH}^{-}}(\Delta \mathrm{x}, \mathrm{t})-\mathrm{C}_{\mathrm{OH}^{-}}(0, \mathrm{t})\right)+\frac{\mathrm{I}_{\mathrm{F}} \Delta \mathrm{x}}{\mathrm{nFAD}_{\mathrm{OH}^{-}}^{\text {sol }}}\left(\text { for } \mathrm{t}<\mathrm{t}^{\mathrm{F}}\right) \\
& \mathrm{C}_{\mathrm{OH}^{-}}(0, \mathrm{t}+\Delta \mathrm{t})=\mathrm{C}_{\mathrm{OH}^{-}}(0, \mathrm{t})+\frac{\Delta \mathrm{t}}{\Delta \mathrm{x}^{2}} \mathrm{D}_{\mathrm{OH}^{-}}^{\text {film }}\left(\mathrm{C}_{\mathrm{OH}^{-}}(\Delta \mathrm{x}, \mathrm{t})-\mathrm{C}_{\mathrm{OH}^{-}}(0, \mathrm{t})\right)+\frac{\mathrm{I}_{\mathrm{F}} \Delta \mathrm{x}}{\mathrm{nFAD}_{\mathrm{OH}}^{\text {sol }}}\left(\text { for } \mathrm{t} \geq \mathrm{t}^{\mathrm{F}}\right)
\end{aligned}
$$

where $\mathrm{D}_{\mathrm{OH}^{-}}^{\text {sol }}$ and $\mathrm{D}_{\mathrm{OH}^{-}}^{\text {film }}$ represent the diffusion coefficients of $\mathrm{OH}^{-}$ions in the solution and the film, respectively. For $0<\mathrm{x}<\mathrm{l}$, the diffusion coefficients of $\mathrm{OH}^{-}$and $-\mathrm{SiOH}$ in the film are concerned.

$$
\begin{aligned}
& \mathrm{C}_{\mathrm{OH}^{-}}(\mathrm{x}, \mathrm{t}+\Delta \mathrm{t})=\mathrm{C}_{\mathrm{OH}^{-}}(\mathrm{x}, \mathrm{t})+\frac{\Delta \mathrm{t}}{\Delta \mathrm{x}^{2}} \mathrm{D}_{\mathrm{OH}^{-}}^{\mathrm{film}}\left(\mathrm{C}_{\mathrm{OH}^{-}}(\mathrm{x}+\Delta \mathrm{x}, \mathrm{t})-2 \mathrm{C}_{\mathrm{OH}^{-}}(\mathrm{x}, \mathrm{t})+\mathrm{C}_{\mathrm{OH}^{-}}(\mathrm{x}-\Delta \mathrm{x}, \mathrm{t})\right) \quad(E q .3) \\
& \mathrm{C}_{-\mathrm{SiOH}}(\mathrm{x}, \mathrm{t}+\Delta \mathrm{t})=\mathrm{C}_{-\mathrm{SiOH}}(\mathrm{x}, \mathrm{t})+\frac{\Delta \mathrm{t}}{\Delta \mathrm{x}^{2}} \mathrm{D}_{-\mathrm{SiOH}}^{\text {film }}\left(\mathrm{C}_{-\mathrm{SiOH}}(\mathrm{x}+\Delta \mathrm{x}, \mathrm{t})-2 \mathrm{C}_{-\mathrm{SiOH}}(\mathrm{x}, \mathrm{t})+\right. \\
& \left.\mathrm{C}_{-\mathrm{SiOH}}(\mathrm{x}-\Delta \mathrm{x}, \mathrm{t})\right)-\Delta \mathrm{tk}_{\mathrm{f}}^{\prime} \mathrm{C}_{\mathrm{OH}^{-}}(\mathrm{x}, \mathrm{t}) \mathrm{C}_{-\mathrm{SiOH}}(\mathrm{x}, \mathrm{t})^{2}
\end{aligned}
$$

$\mathrm{D}_{-\mathrm{SiOH}}^{\mathrm{film}}$ is the diffusion coefficient of $-\mathrm{SiOH}$ in the deposited film. For $\mathrm{x}=1$, one has to consider the diffusion flux both in the film and in the solution:

$$
\begin{aligned}
& \mathrm{C}_{\mathrm{OH}^{-}}(\mathrm{x}, \mathrm{t}+\Delta \mathrm{t})=\mathrm{C}_{\mathrm{OH}^{-}}(\mathrm{x}, \mathrm{t})+\frac{\Delta \mathrm{t}}{\Delta \mathrm{x}^{2}} \mathrm{D}_{\mathrm{OH}^{-}}^{\mathrm{film}}\left(\mathrm{C}_{\mathrm{OH}^{-}}(\mathrm{x}-\Delta \mathrm{x}, \mathrm{t})-\mathrm{C}_{\mathrm{OH}^{-}}(\mathrm{x}, \mathrm{t})\right)+\frac{\Delta \mathrm{t}}{\Delta \mathrm{x}^{2}} \mathrm{D}_{\mathrm{OH}^{-}}^{\mathrm{sol}}\left(\mathrm{C}_{\mathrm{OH}^{-}}(\mathrm{x}+\right. \\
& \left.\Delta \mathrm{x}, \mathrm{t})-\mathrm{C}_{\mathrm{OH}^{-}}(\mathrm{x}, \mathrm{t})\right) \\
& \mathrm{C}_{-\mathrm{SiOH}}(\mathrm{x}, \mathrm{t}+\Delta \mathrm{t})=\mathrm{C}_{-\mathrm{SiOH}}(\mathrm{x}, \mathrm{t})+\frac{\Delta \mathrm{t}}{\Delta \mathrm{x}^{2}} \mathrm{D}_{-\mathrm{SiOH}}^{\mathrm{film}}\left(\mathrm{C}_{-\mathrm{SiOH}}(\mathrm{x}-\Delta \mathrm{x}, \mathrm{t})-\mathrm{C}_{-\mathrm{SiOH}}(\mathrm{x}, \mathrm{t})\right)+\frac{\Delta \mathrm{t}}{\Delta \mathrm{x}^{2}} \mathrm{D}_{-\mathrm{SiOH}}^{\text {sol }}\left(\mathrm{C}_{-\mathrm{SiOH}}(\mathrm{x}+\right. \\
& \left.\Delta \mathrm{x}, \mathrm{t})-\mathrm{C}_{-\mathrm{SiOH}}(\mathrm{x}, \mathrm{t})\right)-\Delta \mathrm{tk}_{\mathrm{f}}^{\prime} \mathrm{C}_{\mathrm{OH}^{-}}(\mathrm{x}, \mathrm{t}) \mathrm{C}_{-\mathrm{SiOH}}(\mathrm{x}, \mathrm{t})^{2}
\end{aligned}
$$


$\mathrm{D}_{-\mathrm{SiOH}}^{\text {sol }}$ is the diffusion coefficient of $-\mathrm{SiOH}$ in the solution. For $\mathrm{x}>\mathrm{l}$, the diffusion coefficients in the solution are considered:

$$
\begin{aligned}
& \mathrm{C}_{\mathrm{OH}^{-}}(\mathrm{x}, \mathrm{t}+\Delta \mathrm{t})=\mathrm{C}_{\mathrm{OH}^{-}}(\mathrm{x}, \mathrm{t})+\frac{\Delta \mathrm{t}}{\Delta \mathrm{x}^{2}} \mathrm{D}_{\mathrm{OH}^{-}}^{\mathrm{sol}}\left(\mathrm{C}_{\mathrm{OH}^{-}}(\mathrm{x}+\Delta \mathrm{x}, \mathrm{t})-2 \mathrm{C}_{\mathrm{OH}^{-}}(\mathrm{x}, \mathrm{t})+\mathrm{C}_{\mathrm{OH}^{-}}(\mathrm{x}-\Delta \mathrm{x}, \mathrm{t})\right) \\
& \mathrm{C}_{-\mathrm{SiOH}}(\mathrm{x}, \mathrm{t}+\Delta \mathrm{t})=\mathrm{C}_{-\mathrm{SiOH}}(\mathrm{x}, \mathrm{t})+\frac{\Delta \mathrm{t}}{\Delta \mathrm{x}^{2}} \mathrm{D}_{-\mathrm{SiOH}}^{\mathrm{sol}}\left(\mathrm{C}_{-\mathrm{SiOH}}(\mathrm{x}+\Delta \mathrm{x}, \mathrm{t})-2 \mathrm{C}_{-\mathrm{SiOH}}(\mathrm{x}, \mathrm{t})+\right. \\
& \left.\mathrm{C}_{-\mathrm{SiOH}}(\mathrm{x}-\Delta \mathrm{x}, \mathrm{t})\right)-\Delta \mathrm{tk}_{\mathrm{f}}^{\prime} \mathrm{C}_{\mathrm{OH}^{-}}(\mathrm{x}, \mathrm{t}) \mathrm{C}_{-\mathrm{SiOH}}(\mathrm{x}, \mathrm{t})^{2}
\end{aligned}
$$

The initial and semi-infinite boundary conditions still apply:

$\mathrm{C}_{\mathrm{OH}^{-}}(\mathrm{x}, 0)=\mathrm{C}_{\mathrm{OH}^{-}}^{*}$

$\mathrm{C}_{\mathrm{OH}^{-}}(\infty, \mathrm{t})=\mathrm{C}_{\mathrm{OH}^{-}}^{*}$

$\mathrm{C}_{-\mathrm{SiOH}}(\mathrm{x}, 0)=\mathrm{C}_{-\mathrm{SiOH}}^{*}$

$\mathrm{C}_{-\mathrm{SiOH}}(\infty, \mathrm{t})=\mathrm{C}_{-\mathrm{SiOH}}^{*}$

The equations above constitute the basis for the numerical simulation, which was programmed by Fortran

95. The source code and the compiled program are attached. They are also available upon request to the authors.

\section{Nomenclature}

\section{Symbol}

$x, \Delta x$

$t, \Delta t$

\section{SI unit Physical meaning}

$\mathrm{m}$

$\mathrm{S}$ length in the axis of film thickness, unit length in simulation time, unit time in simulation

(Other symbols can be found in the main text of the publication.) 